\title{
Modified Triple P Approach by Gynecologic Oncologist-Led Team for Placenta Accreta Spectrum Improves the Outcome: Non-Randomized Controlled Trial
}

\author{
Mohammad Am Ahmed ${ }^{1,2}$, Mostafa M. Khodry ${ }^{1}$ \\ ${ }^{1}$ Gynecologic Oncology Unit, South Valley University, Qena, Egypt \\ ${ }^{2}$ Obstetrics and Gynecology Department, South Valley University, Qena, Egypt \\ Email: drmohammadazsvu@gmail.com
}

How to cite this paper: Ahmed, M.A. and Khodry, M.M. (2019) Modified Triple P Approach by Gynecologic Oncologist-Led Team for Placenta Accreta Spectrum Improves the Outcome: Non-Randomized Controlled Trial. Open Journal of Obstetrics and Gynecology, 9, 1039-1049. https://doi.org/10.4236/ojog.2019.97101

Received: June 18, 2019

Accepted: July 22, 2019

Published: July 25, 2019

Copyright $\odot 2019$ by author(s) and Scientific Research Publishing Inc. This work is licensed under the Creative Commons Attribution International License (CC BY 4.0).

http://creativecommons.org/licenses/by/4.0/

\begin{abstract}
Introduction: Placenta Accreta Spectrum (PAS) is associated with significant maternal and fetal morbidity and mortality. The ideal conservative management still does not exist. We aimed to compare the outcome of cesarean section for PAS by a gynecologic oncologist-led team using the modified triple $\mathrm{P}$ approach and by a non-gynecologic oncologist-led team. Material and Methods: This is non-randomized controlled trial. Group A had Cesarean Section by gynecologic oncologist. Gynecologic oncologist-led team did all Cesarean Section following a modified triple $\mathrm{P}$ approach. The first $\mathrm{P}$ is for "Plan" the uterine incision. The second P for "Pelvic" devascularization by internal iliac artery ligation. The third $\mathrm{P}$ is for Placenta non-separation with resection of the myometrium. Group B had Cesarean Section by non-gynecologic oncologist-led team. The main outcome measures were the need for hysterectomy, amount of blood loss, and the management-related complications. Results: Group A had significantly less estimated blood loss, and received less number of backed RBCs units, and less operative time than group B. The uterus is preserved in all cases of group A and in 50\% of cases of group B. The overall maternal morbidity rate was $17.5 \%$ in group A and $72.2 \%$ in group B. Conclusion: This study provides evidence that the modified triple $\mathrm{P}$ approach for PAS by gynecologic oncologist-led team presents lower maternal morbidity in comparison to surgery by non-gynecologic oncologist-led team.
\end{abstract}

\section{Keywords}

Placenta, Accreta, Gynecologic, Oncologist, Surgery, Outcome 


\section{Introduction}

Placenta Accreta Spectrum (PAS) is an abnormally adherent placenta to the myometrium [1]. It is a major cause of maternal mortality and morbidity [2]. The larger the number of Cesarean sections the woman is, the higher the possibility of PAS is [3]. The diagnosis of PAS is based on the failure of the placenta to separate after delivery of the baby by the usual gentle traction or evidence of visible myometrial invasion at time of surgery. Antenatal imaging may fail [4]. The best anesthetic choice is controversial. However, the evidence supports the use of general or epidural anesthesia over single-shot spinal anesthesia [5]. The timing of elective delivery should be individualized and usually after 34 weeks [6]. The Royal College of Obstetricians and Gynecologists (RCOG) recommend delivery not before 36 - 37 weeks [7].

Currently, there are three treatment options for PAS. The first is an elective hysterectomy. The second is expectant management (leaving the placenta in place). The third is conservative management (removing the placenta) [4] [6]. Elective hysterectomy is the gold standard management but it may not be a preferable choice by some women. Expectant approach is associated with unacceptable high rate of morbidities, reoperation and maternal death [4]. Many researchers tried different techniques to reinforce the outcome of conservative management. This includes resection of part of the myometrium, internal iliac artery embolization/ligation, and uterine sutures. The rate of hysterectomy was $22 \%$ in a large French study from 25 hospitals including 176 women [8]. A more recent conservative approach is the Triple $\mathrm{P}$ approach. It includes perioperative placental localization, pelvic devascularization by embolization of internal iliac arteries, and placental non-separation and myometrial resection. In the modified Triple $\mathrm{P}$ approach, ligation of the internal iliac vessels is used instead of embolization. The frequency of hysterectomy in women who had the modified triple $\mathrm{P}$ approach was 5/35 (14.28\%) [9].

The skills of the main surgeon and the hospital facilities play a major role in the outcome of cesarean section for placenta previa [10]. The aim of this study is to compare the outcome of cesarean section for PAS by a gynecologic oncologist-led team and by a non-gynecologic oncologist-led team.

\section{Material and Methods}

This is non-randomized controlled trial. Because it is unethical to randomize patients with life-threatening condition. We compared data from two groups of women with PAS. Group A "the modified triple P approach group" was managed by Gynecologic oncologist-led team. Group B was a historical group of cases managed by non-gynecologic oncologist-led team. The inclusion criteria for both groups were pregnant women at gestation from 20 - 41 weeks who have placenta previa plus previous Cesarean Section, written informed consent, and failure of placenta to come out with the usual gentle traction during cesarean section. The fourth criterion for group A was the operation by the gynecologic 
oncologist-lead team, and for group B was the operation by the non-gynecologic oncologist-lead team. The exclusion criterion for both groups was women who opt for Cesarean hysterectomy from the start.

Group A patients were recruited cases from the department of Obstetrics \& Gynecology unit, South Valley University, Egypt from $1^{\text {st }}$ of May 2016 until 30 May 2018. The preoperative assessment was by ultrasound with Doppler facility. Preoperative routine investigations were hemoglobin level, platelet count, and prothrombine time \& concentration. We planned all Cesarean Sections at 36 - 37 weeks. Earlier delivery was due to the presence of severe bleeding or other indications as severe preeclampsia. A consultant obstetrician and consultant gynecologic Oncologist did all Cesarean Sections. A consultant anesthesiologist was leading the anesthesia care team. We alerted a consultant urologist, blood bank clinical pathologist in each case. We reserved an intensive care unit (ICU) bed and neonatal intensive care unit (NICU) incubator for each patient. All women received preoperative injections in the form of $1 \mathrm{~g}$ Ceftriaxone, Metoclopramide, and Ranitidine one hour before skin incision. Some cases received blood transfusion before the elective Cesarean Section if hemoglobin level was $<10 \mathrm{~g} / \mathrm{dl}$.

Laparotomy is done through Pfannenstiel's incision under general anesthesia. The following Surgical steps are done: The Triple $P$ approach:

- Plan: The incision of the lower uterine segment (Figure 1). Avoidthe cutting through the placenta. Deliver the baby and ligate the cord. If the placenta did not come out spontaneously, or with gentle traction, then accreta is diagnosed.

- Pelvic devascularization: Ligate the anterior division of the internal iliac artery bilaterally (Figure 2). Leave the placenta in place. If the placenta separates partially, extract it and back the lower uterine segment by gauze. Dissectthe bladder down to the cervico-vaginal junction. Avoid dissection of adherent bladder at the midline. Approach the bladder from the lateral aspect of the vesico-cervical space.

- Placental non-separation and Excision of the myometrium of the anterior lower segment along with the adherent placenta (Figure 3).

All cases received Oxytocin 10 IU by IV infusion by delivery of the baby and $800 \mu \mathrm{g}$ Misoprostol rectally by the end of surgery. Calculate the intraoperative blood loss by weighing the surgical towels and the amount of blood in the suction device. All cases have intraperitoneal drain. The amount of blood loss guides the blood transfusion as decided by the anesthetist. Postoperative hemoglobin level and coagulation profile guide further blood and blood product transfusion. The target was hemoglobin $10 \mathrm{~g} / \mathrm{dl}$ and platelet more than $75 \times$ $10^{6} / \mathrm{L}$.

All cases remained in the recovery room until complete recovery. Shifting women to ICU or regular ward was according to hemodynamic status. Foley Catheter is removed after 12 hours unless there are bladder injury and repair where it is left for 14 days. Intraperitoneal drain is left for $12-24$ hours according to output. All cases have risk assessment and scoring for the need of 


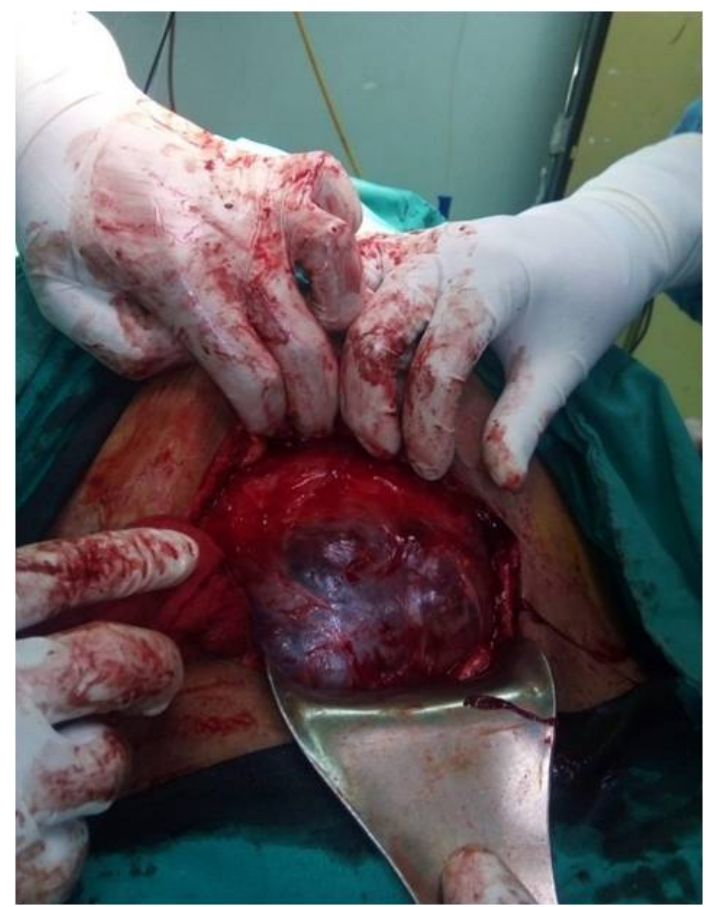

Figure 1. Plan the incision. In placenta previa centralis, the incision is at a high position. In placenta anterior with covering of the scar, the incision would be low.

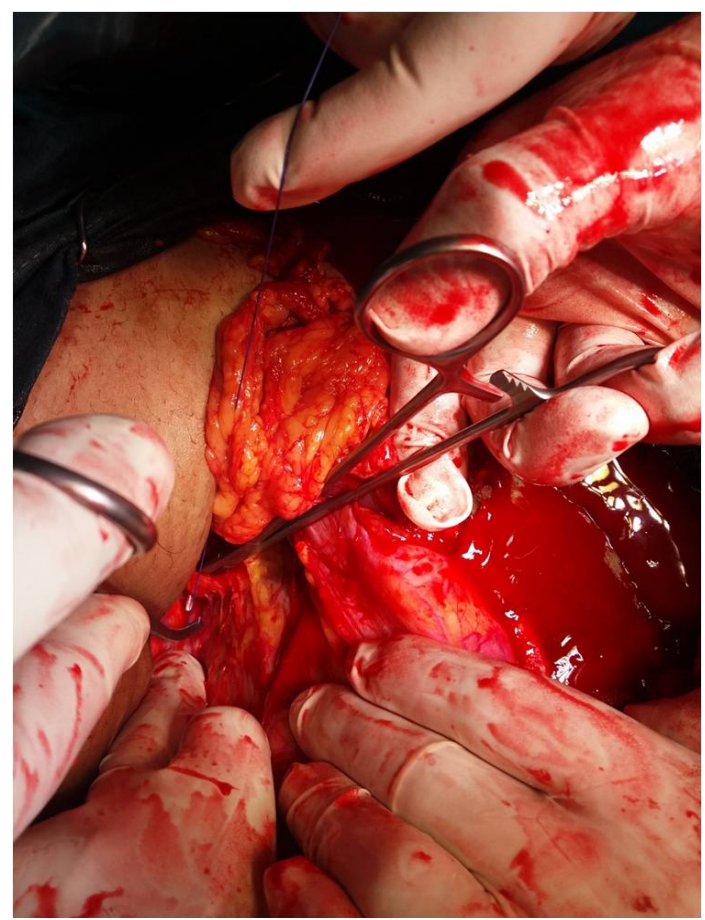

Figure 2. Internal iliac ligation. Incise the peritoneum lateral and parallel to the infudibulo-pelvic ligaments. Blunt dissection in the pararectal space is done. Identify the ureter, external, and internal iliac arteries. Ligate the anterior division of the internal iliac artery. 


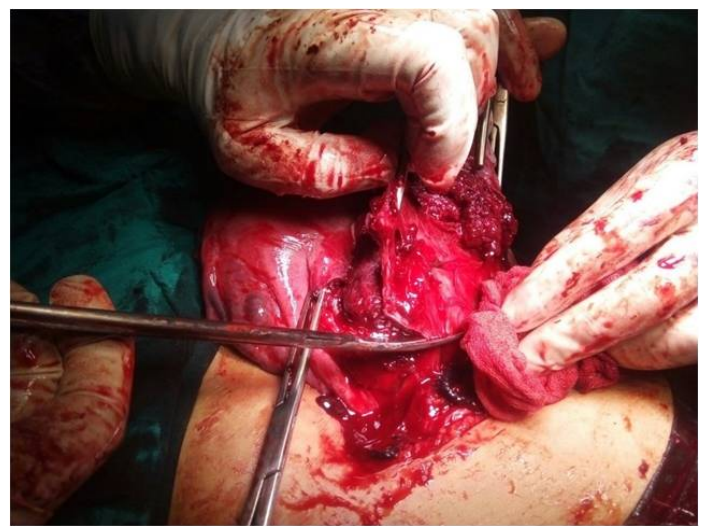

Figure 3. Excise the myometrium with the attached placenta. Reapplying the clamps, like Green Armytage and Kocher's clamps, to control bleeding from the fresh lower segment is helpful in this stage.

thromboprophylaxis. Women maintained postnatal follow up until completing 3 months after delivery.

Group B were women who had surgery for PAS before the establishment of the Gynecologic oncology unit. Data were collected retrospectively from patients' records of the same hospitals throughout the period from first of January 2013 until $30^{\text {th }}$ of December 2015. Patients who had any intervention of the three components of the triple P approach were excluded.

\subsection{Statistical Analysis}

We performed statistical analysis by SPSS version 19 (IBM Corp., Armonk, NY, USA). Analysis of patients' data before, during, and after surgery was done. Data are summarized as mean and standard deviation (SD), median and range, or as percent (\%). Student $t$ test is used to compare means for continuous variables and Chi Square for ordinal and nominal data. Statistical significance was inferred for differences with $\mathrm{P}$ values $<0.05$.

\subsection{Ethical Approval}

The Committee of Ethics for Biomedical Researches, South Valley University approved the research at April 2016. All women in the prospective group had informed written consent.

\section{Results}

During the period from May 1st, 2016 until 30 May 2018, there were 5800 cases of cesarean section. Preoperative suspected PAS based upon Doppler ultrasound and real-time three D ultrasound is found in 84 cases. This gives incidence of 1/69. Intraoperative diagnosis of PAS was found in 57 cases. The historical group included 18 cases of PAS based up on intraoperative data.

Table 1 shows that the perioperative data from women in the modified triple $\mathrm{P}$ approach group and from those in the historical group. There were no differences 
Table 1. Perioperative data.

\begin{tabular}{|c|c|c|c|}
\hline & $\begin{array}{l}\text { Modified triple P group } \\
\text { (Number: } 57 \text { ) }\end{array}$ & $\begin{array}{l}\text { Historical group } \\
\text { (Number: 18) }\end{array}$ & $P$ value \\
\hline Age: mean \pm SD & $29.2 \pm 3.9$ & $28.1 \pm 4.3$ & $>0.05$ \\
\hline \multicolumn{4}{|l|}{ Residency } \\
\hline Urban: Number (\%) & $30 / 57$ & $10 / 18$ & $>0.05$ \\
\hline Rural: Number (\%) & $27 / 57$ & $8 / 18$ & $>0.05$ \\
\hline \multicolumn{4}{|l|}{ Type of admission } \\
\hline Booked cases & $36 / 57$ & $7 / 18$ & $>0.05$ \\
\hline Referral cases & $21 / 57$ & $11 / 18$ & $>0.05$ \\
\hline Gestational age in weeks: mean \pm SD & $35.8 \pm 2.7$ & $35.5 \pm 1.6$ & $>0.05$ \\
\hline Preoperative $\mathrm{Hb}$ : mean \pm SD & $10.4 \pm 0.5$ & $10.1 \pm 0.7$ & $>0.05$ \\
\hline BMI & $25.5 \pm 4.9$ & $21.7 \pm 4.6$ & $>0.05$ \\
\hline \multicolumn{4}{|l|}{ Timing of Surgery } \\
\hline Elective: Number (\%) & $51(89.5 \%)$ & $13(72.2 \%)$ & $>0.05$ \\
\hline Emergency: Number (\%) & $6(10.5 \%)$ & $5(27.8 \%)$ & $>0.05$ \\
\hline No. of previous CS: median (range) & $4(2-6)$ & $4(2-5)$ & $>0.05$ \\
\hline Operative time: minutes (Mean $\pm \mathrm{SD}$ ) & $152.8 \pm 26$ & $200 \pm 34$ & $<0.001$ \\
\hline Estimated blood loss (Mean \pm SD) & $2300 \pm 460$ & $3044 \pm 430$ & $<0.001$ \\
\hline Need for blood transfusion: Number (\%) & $57(100 \%)$ & $18(100 \%)$ & $>0.05$ \\
\hline $\begin{array}{c}\text { Units of backed RBCs transfusion: } \\
\text { median (range) }\end{array}$ & $5(3-8)$ & $8(4-12)$ & $<0.001$ \\
\hline Immediate post-operative $\mathrm{Hb}$ : Mean $\pm \mathrm{SD}$ & $9.7 \pm 0.9$ & $9.2 \pm 1.6$ & $>0.05$ \\
\hline Hospital stay (days): Mean \pm SD & $1.6 \pm 0.6$ & $2.5 \pm 0.9$ & $<0.001$ \\
\hline
\end{tabular}

SD: Standard Deviation; BMI: Body Mass Index; CS: Cesarean Section; RBCs: Red Blood Cells; Hb: Haemoglobin.

between the two groups as regard the patients' age, gestational age, body mass index (BMI), the preoperative hemoglobin, or the timing of the cesarean section whether elective or emergency. The operative time from time of induction of Anesthesia until the time of extubation was significantly longer in the historical group by 50 minutes. All cases both groups received blood transfusion. The women needs about five units of blood transfusion for stabilization in the Modified triple $\mathrm{P}$ approach group and eight units in the historical group. The mean blood loss was significantly higher in the historical group. Clinical decision by the anesthetist to maintain hemodynamic stability of the patient guided the number of units of blood transfusion. We checked the hemoglobin level 12 hours after surgery. Further blood transfusion aimed to keep hemoglobin level above $10 \mathrm{~g} / \mathrm{dl}$. Women in the historical group have significantly longer hospital stay.

Table 2 showed that hysterectomy is not done in any case as an emergency procedure in the Modified triple P approach group. In contrast, eight cases (44.4\%) 
Table 2. Maternal and fetal complications and mortalities.

\begin{tabular}{cccc}
\hline & $\begin{array}{c}\text { Modified triple P } \\
\text { group (Number: 57) }\end{array}$ & $\begin{array}{c}\text { Historical group } \\
\text { (Number: 18) }\end{array}$ & P value \\
\hline & 1) Complications & & \\
\hline Emergency hysterectomy: No (\%) & $0(0 \%)$ & $\mathbf{8}(44.4 \%)$ & $<0.001$ \\
Bladder injury: Number (\%) & $\mathbf{5 ( 8 . 8 \% )}$ & $\mathbf{5 ( 2 7 . 8 \% )}$ & $<0.05$ \\
Ureteric injury: Number (\%) & $0(0 \%)$ & $2(11.1 \%)$ & $<0.05$ \\
NICU admission: Number (\%) & $9(15.7 \%)$ & $6(33.3 \%)$ & $>0.05$ \\
Neonatal mortality: Number (\%) & $4(7 \%)$ & $2(11.1 \%)$ & $>0.05$ \\
ICU admission: Number (\%) & $11(19.3 \%)$ & $11(61.1 \%)$ & $<0.05$ \\
Reoperation: Number (\%) & $0(0 \%)$ & $1(5.5 \%)$ & $>0.05$ \\
Electrolyte disturbance: Number (\%) & $2(3.5 \%)$ & $2(11.1 \%)$ & $>0.05$ \\
Wound infection: Number (\%) & $3(5.2 \%)$ & $2(11.1 \%)$ & $>0.05$ \\
Delayed hysterectomy: Number (\%) & $0(0 \%)$ & $1(5.5 \%)$ & $>0.05$ \\
Long-term complications: Number (\%) & $0(0 \%)$ & $\mathbf{1 ( 5 . 5 \% )}$ & $>0.05$ \\
Total: Number (\%) & $10(17.5 \%)$ & $13(72.2 \%)$ & $<0.001$ \\
\hline
\end{tabular}

ICU: Intensive Care Unit; NICU: Neonatal Intensive Care Unit.

required emergency hysterectomy in the historical group. There were significantly higher rate of bladder injury in the historical group in comparison to the Modified triple $\mathrm{P}$ approach group. Immediate repair by urologist for bladder injury in the Modified triple $\mathrm{P}$ approach group resulted in no postoperative urologic complications. There were two cases of ureteric injury in the historical group and none in the Modified triple $\mathrm{P}$ approach group. Women in the historical group have significantly more admission to the Intensive Care Unit (ICU). Neonatal Intensive Care Unit (NICU) admission and neonatal mortality were not different in both groups. No maternal mortality reported in any of the two groups. Apart from hysterectomy, the total maternal complication rate is $72.2 \%$ in the historical group and $17.5 \%$ in the Modified triple P approach group. No patient had delayed hysterectomy, reoperation, or long-term morbidity throughout the 3 months of postnatal follow up in the Modified triple P approach group. Historical group had one case of reoperation, one case had delayed hysterectomy, and one case of vesico-vaginal fistula. However, this was not statistically different. The total number of hysterectomy in the historical group was $9(50 \%)$.

\section{Discussion}

The ideal management of PAS should involve minimization of blood loss and conservation of the uterus without surgical morbidities. Setting up a team for the 
management of PAS is a challenge. The team must include interested and skilful personnel. The team leader has the duty to check that members and the equipment and the preparation is optimum to avoid losing the precious minutes during the surgery waiting for a staff, blood, materials, or equipment. In this study, we compared data from two group of cases with PAS. A gynecologic oncologist-led team using the modified triple $\mathrm{P}$ approach manages group A. Group B by a non-gynecologic oncologist-led team without the use of any of the components of the triple $\mathrm{P}$ approach.

The incidence of PAS is $1 / 5882$ in UK study [11] and 1/731 from in USA [12]. However, the incidence in our study was $1 / 69$. This incidence does not reflect the actual incidence in the population. The mean blood loss was estimated as $2300 \mathrm{ml}$ in the modified triple $\mathrm{P}$ approach group. This is about $25 \%$ less than that in the historical group. A study from 25 USA hospitals found that the average blood loss was $2000 \mathrm{ml}$ [12]. The amount of blood loss reported from the modified triple $\mathrm{P}$ approach was $1440 \mathrm{ml}$ [9]. There are many factors affecting the calculated amount of blood loss other than the accuracy of the method of calculation. Making attempt to remove the placenta increases the mean blood loss from $1750 \mathrm{ml}$ to $3700 \mathrm{ml}$ [13]. In our study, we sometimes remove the placenta after ligation of internal iliac arteries if there is excessive bleeding from the partially separated placenta. All women required blood transfusion. The median number of blood transfusion units was about five units in the modified triple $\mathrm{P}$ approach group. This is significantly lower than the amount needed in the historical group (8 units). In a retrospective study on 66 cases by Stotler B. et al., they found the incidence of blood transfusion is $95 \%$ (the median RBCs units was 6.5) [14].

We did not have any case of emergency hysterectomy or reoperation in the modified triple $\mathrm{P}$ approach group. This was statistically significant when compared to the outcome in the historical group. The study by Al-Khan A et al. showed that the institution of a team for management of PAS resulted in decrease in the estimated blood loss by $40 \%$ and RBCs transfusion by $50 \%$. The rate of emergency hysterectomy was not significantly different in this study. The team management in this study was based on maternal fetal medicine surgeon, vascular surgeon, urologist, anesthesiologist, neonatologist, and extensive operating room staff [15]. The input of a gynecologic oncologist is highly emphasized in many studies [10] [16]. The literature showed that the success rate of conservative management is also related to the surgical steps. Success rate was $87 \%$ in one large French study including 176 women [8]. More recently, the success rate was $84.3 \%$ using internal iliac artery ligation combined with endosutures in 38 patients [17]. Using the modified triple $\mathrm{P}$ approach in 35 patients achieved success rate of $85.7 \%$ [9]. A stepwise approach including multiple steps in 65 patients avoid hysterectomy in $91.5 \%$ [18]. Many circumstances may affect the surgeon's decision for doing hysterectomy. First, the woman preference; in our society, acceptance of hysterectomy is not easy. Surgeons opt for hysterectomy only in life threatening scenario. Second, the establishment of a team is for the 
management of PAS.

Urinary tract complications are seen in 5 cases $(8.8 \%)$ in the Modified triple $\mathrm{P}$ approach group which is about one-third the rate in the historical group. All cases are managed intraoperatively by urologist without long-term complications. No case of ureteric injury is reported in the Modified triple P approach group. In comparison, two cases of are reported in the historical group. Urinary tract complication is quite common in such patients due to multiple cesarean sections. In addition, the presence of horrible bleeding pushes the surgeon to do rapid dissection of the bladder. Dissection of the bladder from the lower segment allows resection and suturing of the later. Many studies reported urinary tract complication in $6 \%-29 \%$ of cases [17] [18] [19]. NICU admission rate was $15 \%$ in the Modified triple $\mathrm{P}$ approach group. Although this rate is about $50 \%$ lower than the rate in the historical group, it was non-significantly different $(\mathrm{P}$ value is 0.1 ). This rate of NICU admission reflects the mean gestational age at time of delivery that was 35 - 36 weeks. The neonatal mortality is also not significantly different in the two groups. In a UK study including 66 cases of suspected PAS there was no neonatal mortality and the rate of NICU admission was $44 \%$. In that study elective delivery was planned at 35 weeks [13]. NICU admission was more than $50 \%$ in a USA study targeting delivery at 34 weeks [15]. The ICU admission was in $19.3 \%$ of cases in the Modified triple $\mathrm{P}$ approach group which is significantly lower than the rate in the historical group (61.1\%). Cases in the Modified triple $\mathrm{P}$ approach group had $36 \%$ shorter hospital stay than those in the historical group. The study by Al-Khan A et al. showed team management resulted in ICU admission rate of $21 \%$. The overall maternal morbidity rate was $17.5 \%$ in the in the Modified triple $\mathrm{P}$ approach group. The reported overall maternal morbidity and mortality from systematic review in 2012 in cases of PAS was up to $60 \%$ and $7 \%$ respectively [20]. Recent studies, reported a much better outcome in women with suspected PAS. There was no maternal mortality within 158 women managed conservatively or within 31 women managed with emergency peripartum hysterectomy [12] [21].

\section{Conclusion}

The optimum management of PAS should be through an organized institutional team of interested personnel. This study provides evidence that the modified triple P approach for PAS by gynecologic oncologist-led team achieved preservation of the uterus in all cases. Furthermore, it presents a lower maternal morbidity rate when compared to patients done by non-gynecologic oncologist-led team not using the triple $\mathrm{P}$ approach.

\section{Conflicts of Interest}

The authors declare no conflicts of interest regarding the publication of this paper. 


\section{References}

[1] Jauniaux, E., Collins, S. and Burton, G.J. (2018) Placenta Accreta Spectrum: Pathophysiology and Evidence-Based Anatomy for Prenatal Ultrasound Imaging. American Journal of Obstetrics \& Gynecology, 218, 75-87. https://doi.org/10.1016/j.ajog.2017.05.067

[2] Balayla, J. and Bondarenko, H.D. (2013) Placenta Accreta and the Risk of Adverse Maternal and Neonatal Outcomes. Journal of Perinatal Medicine, 41, 141-149. https://doi.org/10.1515/jpm-2012-0219

[3] Marshall, N.E., Fu, R. and Guise, J.M. (2011) Impact of Multiple Cesarean Deliveries on Maternal Morbidity: A Systematic Review. American Journal of Obstetrics \& Gynecology, 205, 262.e261-268. https://doi.org/10.1016/j.ajog.2011.06.035

[4] Loïc, S., Gilles, K., Edwin, C., José, P.J. and Eric, J. (2018) FIGO Consensus Guidelines on Placenta Accreta Spectrum Disorders: Conservative Management. International Journal of Gynecology \& Obstetrics, 140, 291-298.

https://doi.org/10.1002/ijgo.12410

[5] Kuczkowski, K.M. (2011) A Review of Current Anesthetic Concerns and Concepts for Cesarean Hysterectomy. Current Opinion in Obstetrics and Gynecology, 23, 401-407. https://doi.org/10.1097/GCO.0b013e32834cb779

[6] (2012) Committee Opinion No. 529: Placenta Accreta. Obstetrics \& Gynecology, 120, 207-211. https://doi.org/10.1097/AOG.0b013e318262e340

[7] Allahdin, S., Voigt, S. and Htwe, T.T. (2011) Management of Placenta Praevia and Accreta. Journal of Obstetrics and Gynaecology, 31, 1-6. https://doi.org/10.3109/01443615.2010.532248

[8] Sentilhes, L., Ambroselli, C., Kayem, G., Provansal, M., Fernandez, H., Perrotin, F., Winer, N., Pierre, F., Benachi, A., Dreyfus, M., Bauville, E., Mahieu-Caputo, D., Marpeau, L., Descamps, P., Goffinet, F. and Bretelle, F. (2010) Maternal Outcome after Conservative Treatment of Placenta Accreta. Obstetrics \& Gynecology, 115, 526-534. https://doi.org/10.1097/AOG.0b013e3181d066d4

[9] Tskhay, V.B., Yametov, P.K. and Yametova, N.M. (2017) The Use of Modified Triple-P Method with Adherent Placenta Long-Term Results. MOJ Women's Health, 4, 30-32. https://doi.org/10.15406/mojwh.2017.04.00079

[10] Silver, R.M., Fox, K.A., Barton, J.R., Abuhamad, A.Z., Simhan, H., Huls, C.K., Belfort, M.A. and Wright, J.D. (2015) Center of Excellence for Placenta Accreta. American Journal of Obstetrics \& Gynecology, 212, 561-568. https://doi.org/10.1016/j.ajog.2014.11.018

[11] Fitzpatrick, K.E., Sellers, S., Spark, P., Kurinczuk, J.J., Brocklehurst, P. and Knight, M. (2012) Incidence and Risk Factors for Placenta Accreta/Increta/Percreta in the UK: A National Case-Control Study. PLoS ONE, 7, e52893. https://doi.org/10.1371/journal.pone.0052893

[12] Bailit, J.L., Grobman, W.A., Rice, M.M., Reddy, U.M., Wapner, R.J., Varner, M.W., Leveno, K.J., Iams, J.D., Tita, A.T., Saade, G., Rouse, D.J. and Blackwell, S.C. (2015) Morbidly Adherent Placenta Treatments and Outcomes. Obstetrics \& Gynecology, 125, 683-689. https://doi.org/10.1097/AOG.0000000000000680

[13] Fitzpatrick, K.E., Sellers, S., Spark, P., Kurinczuk, J.J., Brocklehurst, P. and Knight, M. (2014) The Management and Outcomes of Placenta Accreta, Increta, and Percreta in the UK: A Population-Based Descriptive Study. Bjog, 121, 62-70. https://doi.org/10.1111/1471-0528.12405

[14] Stotler, B., Padmanabhan, A., Devine, P., Wright, J., Spitalnik, S.L. and Schwartz, J. 
(2011) Transfusion Requirements in Obstetric Patients with Placenta Accreta. Transfusion, 51, 2627-2633. https://doi.org/10.1111/j.1537-2995.2011.03205.x

[15] Al-Khan, A., Gupta, V., Illsley, N.P., Mannion, C., Koenig, C., Bogomol, A., Alvarez, M. and Zamudio, S. (2014) Maternal and Fetal Outcomes in Placenta Accreta after Institution of Team-Managed Care. Reproductive Sciences, 21, 761-771. https://doi.org/10.1177/1933719113512528

[16] Acton, J., Leung, Y., Tan, J. and Salfinger, S. (2014) The Evolving Role of a Gynaecologic Oncologist in a Tertiary Hospital. Australian and New Zealand Journal of Obstetrics and Gynaecology, 54, 26-29. https://doi.org/10.1111/ajo.12146

[17] Rauf, M., Ebru, C., Sevil, E. and Selim, B. (2017) Conservative Management of Post-Partum Hemorrhage Secondary to Placenta Previa-Accreta with Hypogastric Artery Ligation and Endo-Uterine Hemostatic Suture. Journal of Obstetrics and Gynaecology Research, 43, 265-271. https://doi.org/10.1111/jog.13215

[18] Shabana, A., Fawzy, M. and Refaie, W. (2015) Conservative Management of Placenta Percreta: A Stepwise Approach. Archives of Gynecology and Obstetrics, 291, 993-998. https://doi.org/10.1007/s00404-014-3496-x

[19] Perez-Delboy, A. and Wright, J.D. (2014) Surgical Management of Placenta Accreta: To Leave or Remove the Placenta? Bjog, 121, 163-169. https://doi.org/10.1111/1471-0528.12524

[20] Garmi, G. and Salim, R. (2012) Epidemiology, Etiology, Diagnosis, and Management of Placenta Accreta. Obstetrics and Gynecology International, 2012, Article ID: 873929. https://doi.org/10.1155/2012/873929

[21] Uysal, D., Cokmez, H., Aydin, C. and Ciftpinar, T. (2018) Emergency Peripartum Hysterectomy: A Retrospective Study in a Tertiary Care Hospital in Turkey from 2007 to 2015. Journal of Pakistan Medical Association, 68, 487-489.

\section{Abbreviations}

ICU: intensive care unit

NICU: neonatal intensive care unit 